\title{
To tell or not to tell the diagnosis of schizophrenia
}

\author{
Jacqueline M Atkinson University of Glasgow
}

\section{Author's abstract}

Some patients with schizophrenia are not told their diagnosis. The moral, clinical and practical issues involved in telling or not telling the patient are discussed. In some cases a relative is told the diagnosis but not the patient. The implications for the family and clinical outcome are outlined. A case history illustrating some of these issues is presented.

\section{“"Seen The Sunday Times?" \\ 'She didn't think she'd ever heard such bald terror in his voice. In anyone's voice, ever. "That report on them using those injections on the Parkhurst Jail inmates! That's the injections I get!!" She could have sworn he was sobbing. "Read what it says? Eh? - About its proper use being for schizophrenics and psychopaths in mental hospitals? Do you realise that's what I must be????" ' \\ Moira Duff. The Vocation of Pearl Duncan. London: The Women's Press, 1982}

This passage from a novel by Moira Duff describes one of the worst ways a patient can find out his or her diagnosis. The practice of withholding diagnoses from some patients, however, means that this scene is acted out more often than might be necessary. It gives rise to the questions why might it be necessary to keep a diagnosis from someone, and then, as to whether these reasons are valid.

'Circumstances do arise which render it undesirable for a patient to be told the full implications of his condition. Whilst a doctor clearly cannot obtain consent to disclose information, he is not prevented from giving relevant information to a relative or other appropriate person having regard for the particular circumstances' (1).

This paragraph from the British Medical Association's Handbook of Medical Ethics acknowledges that there are 'circumstances' which absolve a doctor from telling a patient the whole truth,

\section{Key words}

Schizophrenia; diagnosis; 'right to know'; patients' rights; relatives' rights. but raises another issue by suggesting that relatives may be told. So we cannot consider the reasons for not telling someone their diagnosis without also considering whether this information will be given to a relative. Not only do 'circumstances' differ between patients and doctors, but the diagnosis itself plays an important part in delineating the circumstances.

Most research and debate centres on what, and how, dying patients should be told, and how far cancer patients in general should be informed about their condition. As Goldie (2) points out: 'There does not appear to be the same debate about telling patients they have disseminated sclerosis or coronary disease as there is with cancer'. Much of the reasoning, as well as the emotion, in the discussion stems from the premise that the issue only involves a fatal, or potentially fatal disease. They are not, however, the only people for whom being told their diagnosis is an important issue.

Focussing on patients with a diagnosis of schizophrenia involves a re-examination of the 'circumstances' which impinge on the decision 'to tell or not to tell'.

\section{Not to tell}

Whilst many psychiatrists always disclose diagnosis, some do not tell any patients they have schizophrenia and others do not tell some of this group their diagnosis. The reasons given are broadly similar to the three usually given for misleading patients with fatal illnesses (3) as well as special variations of these. That there is genuine concern for the impact of knowing the diagnosis on the patient is not disputed.

Firstly, the dictate 'do no harm' is invoked, allowing the doctor to override other issues such as deception or the individual's rights to truth and information. Harm is usually taken to mean adding to the patient's problems by creating or increasing despair, anxiety or depression, and in psychiatric illness we may add low self-esteem. When this argument is used it seems to be suggested that these additional problems may exacerbate psychiatric symptoms and may compound the acute phase or lead to relapse. Although, inevitably, some people may respond with despair, there is no research evidence on the outcome of this, or whether it contributes to an exacerbation of symptoms or relapse. 
The possible negative effect on patients warrants some investigation. Are there long-term deleterious consequences or is the process more akin to that of grief? Patients (and relatives) who are told diagnoses such as cancer, or of a terminal illness, go through a period of shock and disbelief, denial, rejection, anger, bitterness or despair before coming to terms with their condition, in terms of acceptance and resolution. It seems entirely possible that the diagnosis of schizophrenia may evoke a similar sequence, and that negative responses should be expected before the patient (and relative) is able to accept and deal with the knowledge. This may be likened to a period of grief and mourning for the person who has been 'lost'. Such a sequence of responses to being told the diagnosis implies that the psychiatrist or other team members will have to become involved in counselling, supporting and educating patients (and relatives).

A further area of 'harm' has to be considered in psychiatry, and that is the social effect of being labelled 'schizophrenic'. The public's attitudes to, and misconceptions of, mental illness are too wide an issue to enter in to here, and are documented elsewhere $(4,5)$. If, however, a person is behaving in such a way as to draw attention to him or herself, then the public will react to this, regardless of how that individual has been 'officially labelled'. There is no obligation for patients to share the information of their diagnosis with others, and thus the concern for its harmful social effects seems out of proportion.

The second argument for 'not to tell' involves the uncertainty principle: that a doctor can never entirely be sure of the diagnosis or prognosis, particularly of schizophrenia. In the case of conveying information to a patient truthfulness must surely mean what one believes to be true, based on knowledge and experience, rather than abstract and absolute truth.

The issue of purposeful and non-purposeful misdiagnosis is dealt with in some detail by Reich (6). Purposeful misdiagnosis is a conscious decision under pressure from the patients, their relatives, hospital or political authorities for some specified end. Nonpurposeful misdiagnoses arise from more subtle and insidious pressures within psychiatry itself. Reich cites three major sources of misdiagnosis, namely 'the inherent limitations of the diagnostic process' and its vulnerability to error, 'the power of the diagnostic theory to shape psychiatric vision', and 'the beauty of diagnosis as a solution to human problems'. This last category encompasses diagnosis as: 'explanation, mitigation and exculpation', 'reassurance', 'exclusion and dehumanisation', 'self-confirming hypothesis' and 'discreditation and punishment'. Although many of these assumptions and implications surrounding diagnosis have a negative outcome, some are positive, and will be taken up in the next section.

One solution to the problem of possibly erroneous diagnosis has been found by a small number of psychiatrists who refuse to diagnose anyone as schizophrenic, choosing some other less 'medical' label. Another group choose only to use the term within medical circles, but to all patients, not just in certain circumstances, use terms such as 'nervous breakdown', 'emotional breakdown', 'problems with your self-confidence' or some other vague, meaningless phrase.

Still others believe that to label a person schizophrenic on one episode is unwarrantably speedy, so use one of the above devices for dealing with the patient whilst waiting for a second episode. This group may have the strongest argument for slow delivery of diagnosis, for clearly they cannot say: 'We think you have schizophrenia but we're waiting for a second episode before we finally decide'. (This argument also defines schizophrenia as a recurring illness.)

The argument that prognosis in schizophrenia may be uncertain overlooks the very real evidence we have regarding outcome and particular variables $(7,8,9)$. It also seems to imply that the psychiatrist would never discuss the future, with or without diagnosis, which, if true, would be most unjust to the patient. Furthermore, it seems to suggest that a diagnosis would be given in isolation and that patients would be left to make their own conclusions. No one, surely, would suggest that a diagnosis, or any other information, should be given without putting it in context, giving other relevant information and allowing the patient to discuss the issues involved.

The third major argument, namely that patients do not want to be told their diagnosis is probably less relevant here. It may interact with argument one, and then the belief becomes 'people do not want to be told because of the harm it would do them'.

There is a final argument which seems to occur more in psychiatry than other specialties, and that is that such revelations may adversely effect the doctorpatient relationship. This is a more sophisticated argument than simply 'the patient won't like me any more' and involves the nature of schizophrenia itself. Premises within the argument include: since people with schizophrenia usually lack insight, to tell them they are schizophrenic will not be accepted and will therefore be pointless; or that to give this information to people who are paranoid will only increase their paranoia as they will believe that the doctor has now turned against them.

It may be that the psychiatrist's inability to 'cure' or even, sometimes adequately manage, schizophrenia make it difficult in some cases to acknowledge the diagnosis and may contribute to lack of trust in the doctor by the patient.

\section{To tell}

The arguments put forward for telling patients with schizophrenia their diagnosis fall into three main groups; the moral argument, clinical arguments and practical arguments. As might be expected these groups are not discrete and there is some overlap.

The moral argument, as with other diagnoses, centres around the patient's 'right to know', and the 
ethics of lying to patients (through omission as well as commission) which undermines the principle of respect for persons and, indeed, the autonomy of the person himself. This line of reasoning has been well argued elsewhere (10) and need not be rehearsed again here.

In instances where the family is told but not the patient, the patient's right to autonomy is further compromised. The issues involved in this circumstance will be discussed in the next section.

As might be expected most of the arguments for telling patients are of a clinical nature. Some of these seem very close to Reich's 'beauty of diagnosis as a solution to human problems'. Telling someone she has schizophrenia gives her both an explanation of her behaviour and a reason for it. She is no longer isolated in her own set of problems but one of a large patient population with the same diagnosis and problems in common.

Furthermore, diagnosis can be a positive clinical tool in dealing with issues of guilt and blame. Both patients and families may be able, within the context of discussing the diagnosis, to deal with feelings of either deserving to be ill because of past behaviour, or of having treated the patient in such a way as to cause the illness, or of blaming another family member for causing the illness through his/her treatment of the patient. Dealing with a patient's or family's search after meaning can only begin to be dealt with once the diagnosis has been divulged.

In the same way it is easier to discuss treatment and the control of symptoms when these are put in the context of a specific diagnosis. The need for medication on a long-term basis, as a measure to prevent future relapses, as well as to control acute symptoms becomes a more reasonable proposition for the patient. It is also possible to discuss with the patient (and family) early warning signs of impending relapse and the possibility of increased medication to prevent or diminish the effect of such relapse.

Lastly we come to the practical reasons for telling patients their diagnosis. The most basic is the belief that the patient will find out eventually, anyway. The opening example is not uncommon. Patients see their case notes, either inadvertently or deliberately; they look their symptoms up in medical books; they find out their medication and look that up, or another patient tells them what it is for; a staff member accidentally lets slip the diagnosis; someone suggests the diagnosis as a joke ... and so on. The possibilities are, if not limitless, many and varied.

Finding out the diagnosis in such circumstances can disrupt the doctor-patient relationship causing distrust and tension due to lack of openness. It means that the patient cannot discuss his worries and anxieties about his condition and future with the person who ought to be available for such discussion. This is particularly important when schizophrenia becomes an issue of public debate in connection with crimes of violence; for example, the Peter Sutcliff trial (1981), or the
Hungerford massacre (1987). At such times both patients and families need a forum where they can discuss their fears.

\section{Telling only the family}

In some cases the family, but not the patient, may be told the diagnosis. Again this happens with terminal patients and encompasses those reasons cited earlier in not telling the patient.

The consequences of this, however, include tension in the family, restriction on speech, mistrust, suspicion and an extensive web of lies which is hard to maintain. It may be that doctors and relatives believe the deceit to be sustainable during the last period of a terminal illness, but schizophrenia is not terminal. Schizophrenia is a long-term illness with many and varied attendant problems, not least day-to-day management. It is not possible to lie to the patient 'for the best' knowing that such a lie will be for a limited period; it means living a lie daily, possibly for years and years.

Relatives are put in an impossible practical as well as moral position. If the patient asks 'Do you know what is wrong with me?' how should they reply? To lie or not to lie? And if to lie, how to deal with the consequences?

And if not to lie, then what? It is not the relatives' responsibility to tell their child or spouse they have schizophrenia. Arguably, they are the worst people so to do. Not only are they often ill-informed themselves (11) but they are likely to have difficulty in coming to terms with the diagnosis too. Their emotional involvement with the patient may make them want to protect the patient from the full knowledge of the condition, or lead to emotionally charged discussions which are not helpful. If they tell the truth they are illequipped and ill-prepared to deal with the consequences.

Lying itself may be accompanied by feelings of guilt and shame, and the family has to be alert to the possibility of others knowing the diagnosis and letting it slip. They might be prevented from getting advice and help in coming to terms with the problem from one of the self-help groups because of the deceit involved; or compound the lies to attend such a group. The National Schizophrenia Fellowship (Scotland) recently agreed that they would continue to send out their newsletter in brown envelopes rather than clear plastic (although more expensive) because of the number of families who, on joining, had specified that the word 'schizophrenia' must never appear on the outside of any mail as the patient was not aware of his diagnosis.

If, or when, the patient does find out his diagnosis, and realises that his family has known for some time, then the resulting mistrust, and possible exacerbation of paranoia, may fracture an already delicate relationship beyond repair.

\section{Case history}

The patient, a man of twenty-one, was diagnosed as 
having schizophrenia three years previously. He lived at home with his parents, had had to give up his studies and had not been able to hold down a job. He had not been told his diagnosis.

His parents, however, were told almost at the start that their son had schizophrenia, but nothing else. After a year of bewilderment and despair they found the National Schizophrenia Fellowship (Scotland) and attended the monthly meetings regularly. To do so they had to lie, saying they were going to visit an elderly aunt. One evening the son suggested going with them. Since he tended to avoid others and never initiated activities this seemed particularly unusual and they felt he did not believe their excuses, either about where they were going or for not taking him.

Of above average intelligence the patient read a lot, particularly books on psychiatry and mental illness. He left books lying around the house open at the pages on schizophrenia. His parents, not unnaturally; believed he was trying to tell them he knew what was wrong with him, or was seeking confirmation from them that this was, or was not, his problem. They tried to discuss the issue with the psychiatrist, only to hear that he still didn't think their son should be told, but with no explanation as to why not. Eventually he did admit that he didn't think 'the boy could handle it'.

Tension increased in the family as the son worried aloud about his condition, why he had to stay on medication, and particularly his future. His parents felt unable to respond honestly, yet could not bring themselves to lie deliberately. Thus the patient was left with no frame of reference, no information, no support and no way of being able to make rational decisions for himself.

This situation might have continued indefinitely but for a quirk of fate.

Although receiving disability benefit the son was still trying to find a job and applied for one advertised at the Job Centre. In time he telephoned the Job Centre to enquire about the outcome and was overheard by his mother. By his tone of voice and expression she knew something dramatic had happened, but all the son said was he had been told he wasn't suitable and that he was going for a walk. He left the house immediately.

The mother telephoned the Job Centre straightaway and spoke to the man who had dealt with her son, finding out that he had told her son that he wasn't suitable for the job 'because of his schizophrenia'.

The ending to this story is more positive than might have been hoped. The son returned home and was able to discuss the matter with his parents freely and openly. He was able to understand and forgive his parents their deception, although all three felt considerable resentment against the psychiatrist. Since then he has been able to attend $\mathrm{NSF}(\mathrm{S})$ meetings with his parents and learn more about his condition, despite a psychiatrist who still maintains 'it's not a good idea'.

\section{Conclusions}

When a psychiatrist withholds a diagnosis from a patient he is denying the patient knowledge about his condition and a framework in which to plan for the future and manage his behaviour. By telling only relatives a psychiatrist may contribute to tension in the family. He may also, subliminally, be contributing to the myths about schizophrenia by implying that it is too terrible to tell the patient and too awful to discuss. How to tell patients and relatives the diagnosis is not the subject of this paper, but it clearly involves an open, honest atmosphere in which questions can be raised and answered and, probably, some form of ongoing support.

Facqueline $M$ Atkinson $P h D$ is a Lecturer in the Department of Community Medicine, University of Glasgow, 2 Lilybank Gardens, Glasgow G4 9ED. She is also a member of the National Schizophrenia Fellowship (Scotland) Management Committee.

\section{References}

(1) British Medical Association. Handbook of medical ethics. London: BMA, 1982: 13.

(2) Goldie L. The ethics of telling the patient. Fournal of medical ethics 1982; 8:128-133.

(3) Anonymous. On telling dying patients the truth [editorial]. Fournal of medical ethics 1982; 8:115-116.

(4) Nunnally J C jr. Popular conceptions of mental health: their development and change. New York: Holt, Reinhart and Winston, 1961.

(5) Crocetti G M, Spiro H R, Siassi I. Contemporary attitudes toward mental illness. Pittsburgh: University of Pittsburgh Press, 1974.

(6) Reich W. Psychiatric diagnosis as an ethical problem. In: Bloch S, Chodoff P, eds. Psychiatric ethics. Oxford: Oxford University Press, 1982.

(7) Lukoff D, Snyder K, Ventura J, Nuechterlein K H. Life events, familial stress and coping in the developmental course of schizophrenia. Schizophrenia bulletin 1984; 10:258-292.

(8) Fenton W S., McGlashan T H. Prognostic scale for chronic schizophrenia. Schizophrenia bulletin 1987; 13:277-286.

(9) Gaebel W, Pietzcher A. Prospective study of course of illness in schizophrenia: part II prediction of outcome. Schizophrenia bulletin 1987; 13:299-306.

(10) Downie R S, Calman K C. Healthy respect - ethics in health care. London: Faber and Faber, 1987.

(11) Berkowitz R, Eberlein-Fries R, Kuipers L, Leff J. Educating relatives about schizophrenia. Schizophrenia bulletin 1984; 10:418-429. 